\title{
Study and Comparison of the Thermomechanical Response of Geopolymeric and Conventional Concretes
}

\author{
F.A. Huamán-Mamani1, J.F. Gamarra-Delgado', J.J. Paredes-Paz¹, V.C. Bringas-Rodríguez¹, \\ D.L. Mayta-Ponce ${ }^{1}$ and G.P. Rodríguez-Guillén' ${ }^{1}$ \\ ${ }_{1}^{1}$ Grupo de Investigación en Ciencia y Tecnología de Materiales, Departamento de Ciencias Naturales, Universidad \\ Católica San Pablo, Arequipa, Perú \\ Urb. Campiña Paisajista, Quinta Vivanco s/n, Arequipa 04001, Perú \\ fhuaman@ucsp.edu.pe; frank.gamarra23@gmail.com; janice.paredes@ucsp.edu.pe; veronicawnh@gmail.com; \\ dlmayta@ucsp.edu.pe; gprodriguez@ucsp.edu.pe
}

\begin{abstract}
Geopolymers are a class of inorganic synthetic materials that in recent years have received extensive interest of the scientific community, mainly due to the variety of applications in which they can be used. The synthesis of these materials is based on a chemical process called geopolymerization, which consists of the alkaline activation of amorphous alumina and silica oxides present in many natural raw materials and industrial solid waste. Therefore, the present work proposes the use of inorganic mining residues (mine tailings) from gold mining in the southern region of Peru, for the manufacture of geopolymeric concrete. The first part of the research focused on the physical, structural and microstructural characterization of the raw material (fine sand and mining tailings), then the volumetric matrix of mixtures for five types of geopolymer concrete was determined. Cylindrical samples of $20 \mathrm{~mm}$ diameter and 40 $\mathrm{mm}$ high geopolymeric concrete were manufactured, at the same time conventional Portland cement concrete was manufactured for comparison purposes. All materials were mechanically characterized by uniaxial compression tests at variable temperatures (from room temperature to $600 \stackrel{\circ}{\circ} \mathrm{C}$ ), and they were also microstructurally characterized before and after mechanical tests. The main microstructural mechanisms responsible for the fracture and plastic deformation of geopolymeric and conventional Portland cement concretes have been determined.
\end{abstract}

Keywords: Construction, thermomechanical, geopolymer concrete, conventional concrete; mining tailings

(C) Copyright 2020 Authors - This is an Open Access article published under the Creative Commons Attribution License terms (http://creativecommons.org/licenses/by/3.0). Unrestricted use, distribution, and reproduction in any medium are permitted, provided the original work is properly cited.

\section{Introduction}

Geopolymers are a class of inorganic synthetic materials obtained at room temperature by a chemical process called geopolymerization, which consists of the solubilization of amorphous phases of aluminosilicates present in industrial solid waste, calcined clays, natural minerals, among others, by the action of a alkaline activator in aqueous solution [1,2]. Geopolymers have received extensive interest of the scientific community in recent years, mainly due to the variety of applications in which they can be used, this derived from their excellent fire resistance, low density, low cost, easy manufacturing, excellent chemical/thermal stability and eco-friendly synthesis $[3,4]$.

For some years these materials have been considered revolutionary for their potential use as an alternative material to ordinary Portland cement $[5,6]$. Several research papers have reported that geopolymeric concretes have the capacity to develop up to $70 \%$ of maximum compressive strength within the first 4 hours of curing at an appropriate temperature [7], unlike Portland cement concretes which require up to 28 days to achieve maximum mechanical resistance. On the other hand, geopolymeric concrete shows very little shrinkage due to drying, it was found that after one year it presents between 5 to 7 times less shrinkage than Portland cement concrete $[8,9]$. On the other hand, several works have shown the negative influence of sulfates on Portland cement concrete, which drastically reduces its mechanical resistance to compression, this reduction is explained by the reaction of sulfates with the calcium present in Portland cement, which leads to the 
formation of gypsum and ettringite [10], which are phases that require a greater volume and therefore their formation generates internal stresses in the Portland cement concrete, which then lead to nucleation and propagation of cracks. On the other hand, geopolymeric concrete does not present similar problems because its properties depend on other types of reactions (in the absence of calcium) $[11,12]$

Geopolymeric concretes exhibit good mechanical response to high temperatures compared to their Portland cement concrete counterparts; in this regard, Kong et al. [12] studied the mechanical behavior of Portland cement and geopolymer pastes after being subjected to high temperatures, finding that while at 800 ${ }^{\circ} \mathrm{C}$ the geopolymer paste improves its resistance to compression, Portland cement paste, at $400{ }^{\circ} \mathrm{C}$, lost all its residual resistance, this loss of resistance of the Portland cement paste was attributed to the decomposition of $\mathrm{Ca}(\mathrm{OH})_{2}$ at approximately $400{ }^{\circ} \mathrm{C}$. One of the most important materials in the composition of conventional concretes is Portland cement, which is basically a mixture of gypsum and clinker, the latter is obtained by calcining limestone and clay at temperatures between 1350 and $1450{ }^{\circ} \mathrm{C}$. Obtaining the Clinker is accompanied by large $\mathrm{CO}_{2}$ emissions. In this regard, it has been determined that a cement kiln produces approximately 0.8 tons of $\mathrm{CO}_{2}$ for every ton of Portland cement [13]. On the other hand, the accumulation of large amounts of mining tailings, as a consequence of mining in Peru, constitutes one of the main environmental problems in our region. Currently, there is not an adequate mining waste management system, therefore, it is important to consider new alternatives for the use of this waste [14-16].

\section{Materials and methods}

\subsection{Raw materials}

Geopolymer concrete (GC) were prepared by geopolymerization of mining tailings dust (MT), provided by the company CEPROMET SAC (Peru), and a $9 \mathrm{M}$ aqueous solution of $\mathrm{Na}(\mathrm{OH})$, with the addition of a controlled amount of fine sand (FS) ). At the same time, conventional concrete samples (CCs) were prepared from the mixture of Portland cement (PC), FS and water. The matrix of mixtures of GCs and CCs was determined with the help of the Simplex Lattice experimental model. Tables 1 and 2 show the mix matrix for GCs and CCs, respectively.
Table 1: Mixing matrix for GCs.

\begin{tabular}{ccc}
\hline \multirow{2}{*}{ code } & \multicolumn{2}{c}{ volume $(\%)$} \\
\cline { 2 - 3 } & MT & FS \\
\hline GC-MT62.5 & 62.5 & 37.5 \\
\hline GC-MT50.0 & 50.0 & 50.0 \\
\hline GC-MT25.0 & 25.0 & 75.0 \\
\hline GC-MT75.0 & 75.0 & 25.0 \\
\hline GC-MT37.5 & 37.5 & 62.5 \\
\hline
\end{tabular}

Table 2: Mixing matrix for CCs.

\begin{tabular}{ccc}
\hline \multirow{2}{*}{ code } & \multicolumn{2}{c}{ volume $(\%)$} \\
\cline { 2 - 3 } & PC & FS \\
\hline CC-PC62.5 & 62.5 & 37.5 \\
\hline CC- PC50.0 & 50.0 & 50.0 \\
\hline CC- PC25.0 & 25.0 & 75.0 \\
\hline CC- PC75.0 & 75.0 & 25.0 \\
\hline CC- PC37.5 & 37.5 & 62.5 \\
\hline
\end{tabular}

\subsection{Sample Preparation}

Adequate amounts of binder (MT or PC) and FS were ground in an alumina mortar and then sieved separately on an ASTM \# 140 sieve $(106 \mu \mathrm{m})$, then based on $20 \mathrm{~g}$. of powder mixes and with the matrices of mixes of tables 1 and 2 GCs and CCs were prepared. In the case of GC samples, MT powder and $10 \mathrm{ml}$ of $\mathrm{Na}(\mathrm{OH})$ solution were mixed for 5 minutes, then the corresponding mass of FS was added and mixed for another 5 minutes, the GC paste obtained was compacted for 5 minutes at $60 \mathrm{MPa}$ in a $20 \mathrm{~mm}$ diameter hardened steel cylinder mold. In the case of CC samples, the PC powder was mixed for 5 minutes with $10 \mathrm{ml}$ of drinking water, the following preparation steps were similar to those followed GC samples. The cylindrical specimens of GC and CC obtained were placed in hermetic bags for 7 days and then dried in an oven at $60^{\circ} \mathrm{C}$ for 24 hours.

\subsection{Physical, Structural, Microstructural and Mechanical Characterization}

For the determination of the real density and particle size distribution, helium pycnometry and light laser diffraction granulometry techniques were used, respectively (Laboratory of functional characterization, CITIUS, Universidad de Sevilla, Spain). On the other hand, $\mathrm{X}$-ray diffraction tests were carried out on the starting powders, for the determination of the crystalline phases present, a Bruker D8 Advance A25 X-ray diffractometer with $\mathrm{Cu} \mathrm{K} \alpha$ radiation and $\mathrm{Ni}$ filter was used, equipped with Scintillation detector in Bragg-Bentano $\theta-2 \theta$ configuration (X-ray laboratory, CITIUS, Universidad de Sevilla, Spain). 
The microstructural characterization of the starting materials and polished surfaces of GC and CC samples was performed by optical microscopy (Research Laboratory of the Universidad Católica San Pablo, Peru) and electron microscopy (Laboratory of microscopy, CITIUS, Universidad de Sevilla, Spain), For the GC and CC samples, a careful preparation of the observation surfaces was carried out, which included: cutting with a diamond-edged disc, roughing with $\mathrm{SiC}$ abrasive paper and mechanical polishing with diamond paste of $9,6,3$ and $1 \mu \mathrm{m}$.

Parallelepiped prisms of $10 \times 5 \times 5 \mathrm{~mm}$ were cut from larger cylindrical specimens of prepared GCs and CCs. The prisms obtained were used in the thermomechanical tests carried out at a constant compression speed of $0.05 \mathrm{~mm} / \mathrm{min}$. and variable temperature. A MICROTEST brand electromechanical universal testing machine, model EM1/50/FR (Spain) was used. The raw force-displacement data was analyzed in stress vs. strain curves.

\section{Results and Discussions}

\subsection{Phases, Particle Size and Morphology of Starting Materials}

The data obtained by helium pycnometry revealed average real density values of 3.07 and $2.83 \mathrm{~g} \mathrm{/} \mathrm{cm}^{3}$ for FS and MT particles, respectively. Furthermore, XRD tests revealed the presence of five crystalline phases in FS: Albite $\left(\mathrm{Na}\left(\mathrm{Si}_{3} \mathrm{Al}\right) \mathrm{O}_{8}\right)$, Gypsum $\left(\mathrm{CaSO}_{4} * 2 \mathrm{H}_{2} \mathrm{O}\right)$, Quartz $\left(\mathrm{SiO}_{2}\right)$, Potassium Magnesium Aluminum Fluoride Silicate $\quad\left(\mathrm{KMg}\left(\mathrm{Si}_{3} \mathrm{Al}\right) \mathrm{O}_{10} \mathrm{~F}_{2}\right) \quad y \quad$ Fluoro-edenite $\left(\mathrm{NaCa}_{2} \mathrm{Mg}_{5} \mathrm{Si}_{7} \mathrm{AlO}_{22} \mathrm{~F}_{2}\right)$, and nine crystalline phases in MT: Muscovite $\left(\mathrm{KAl}_{2} \mathrm{Si}_{3}\right)$, Quartz $\left(\mathrm{SiO}_{2}\right)$, Orthoclase $\left(\mathrm{KAlSi}_{3} \mathrm{O}_{8}\right)$, Pyrite $\left(\mathrm{FeS}_{2}\right)$, Calcite (CaCO3), Sulfur (S), Actinolite $\left(\mathrm{Ca}_{2}\left(\mathrm{Mg}, \mathrm{Fe}^{+2}\right)_{5} \mathrm{Si}_{8} \mathrm{O}_{22}(\mathrm{OH})_{2}\right), \quad$ Hydrogen Arsenate Hydrate $\left(\mathrm{As}_{2} \mathrm{O}_{5}{ }^{*} 4 \mathrm{H}_{2} \mathrm{O}\right)$ y Arsenolite $\left(\mathrm{As}_{2} \mathrm{O}_{3}\right)$.
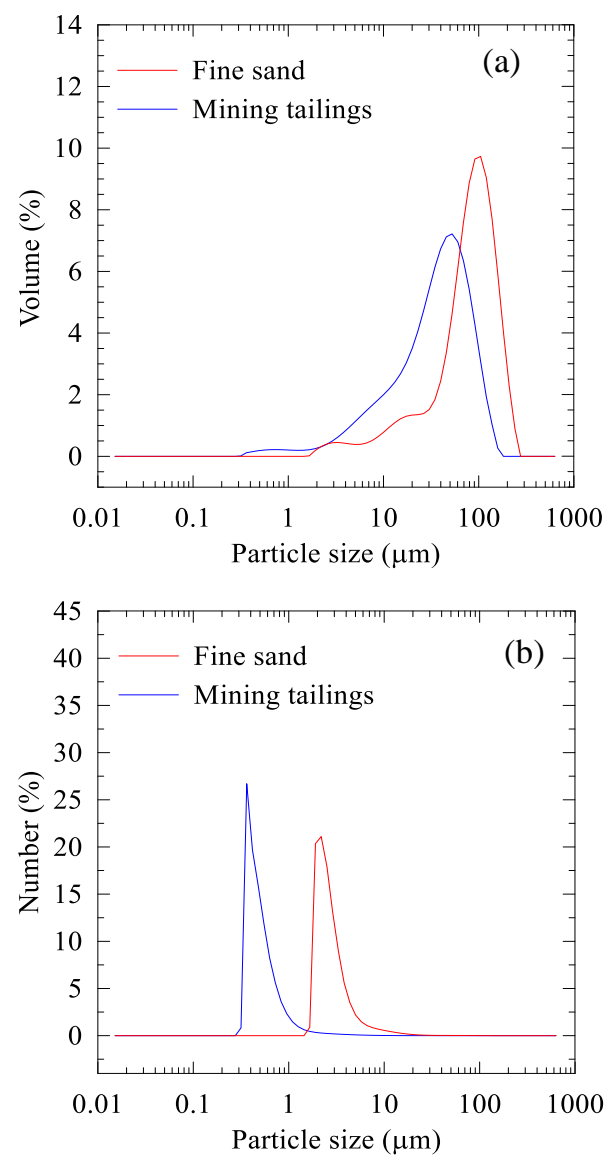

Fig. 1: Particle size distribution in (a) volume and (b) number for MT (blue line) and FS (red line).

Figure 1 shows the particle size distributions, in volume and number, of FS and MT, it is observed that the particle size distributions of MT are, in number and volume, in a range of finer sizes with respect to those of FS, in addition, the mean particle size, according to the volume distribution, is approximately 100 and $40 \mu \mathrm{m}$ for the FS and MT sample, respectively. It should be noted that the distribution of particle sizes in number (Figure 1 (b)) indicates that in both types of samples there is a markedly greater number of fine particles compared to those of larger size, therefore in this type of distribution apparently not particles of sizes greater than 2 and 20 $\mu \mathrm{m}$ would exist for MT and FS, respectively.

Figure 2 shows Scanning Electron Microscopy (SEM) micrographs of FS (Figure 2 (a)) and MT samples (Figure 2 (b)). There are notable differences in terms of particle sizes, with the FS being the largest, and it was also possible to verify that the FS particles are mostly angular and the MT rounded. These results are in good agreement with that observed in the particle size distributions of Figure 1. 

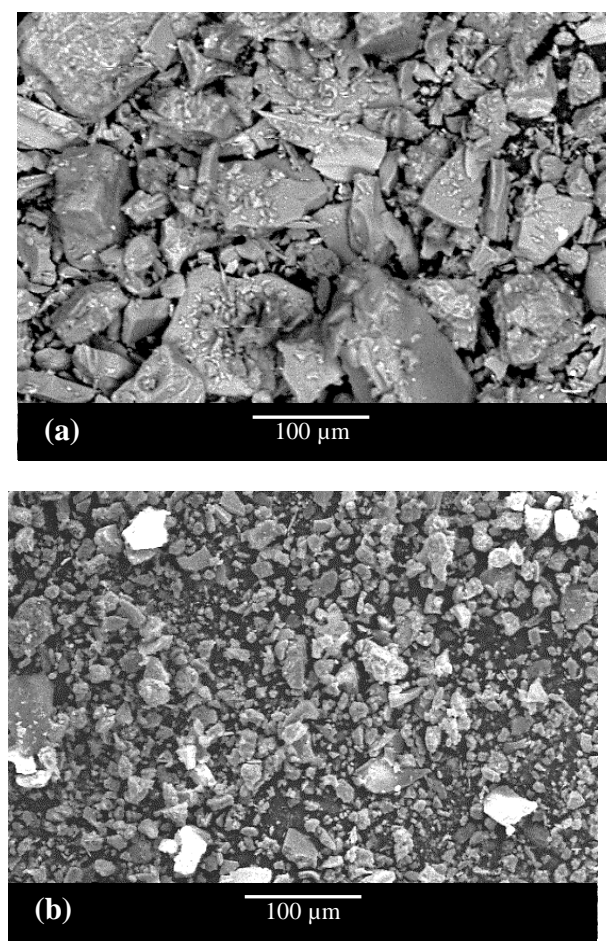

Fig. 2: SEM micrographs of (a) FS and (b) MT.

\subsection{Morphology of Geopolymeric and Conventional Concretes}

Polished surfaces were observed directly without application of any metallographic attack. In Figure 3 we present optical microscopy micrographs of polished surfaces of GC and CC samples with $37.5 \%$ of binder phase (MT or PC). Figure 3 (a) shows that the GCs microstructure consists of two well differentiated phases, on the one hand, a continuous dark contrast geopolymer phase (alkaline activated MT), and on the other, a dispersed phase of light contrast of FS particles (clear phase) located within the geopolymer phase. Similarly, the morphology of CC samples shown in Figure 3 (b) consists of a discontinuous phase of dark gray and black FS contrast grains located within a continuous phase of light gray contrast, corresponding to PC.
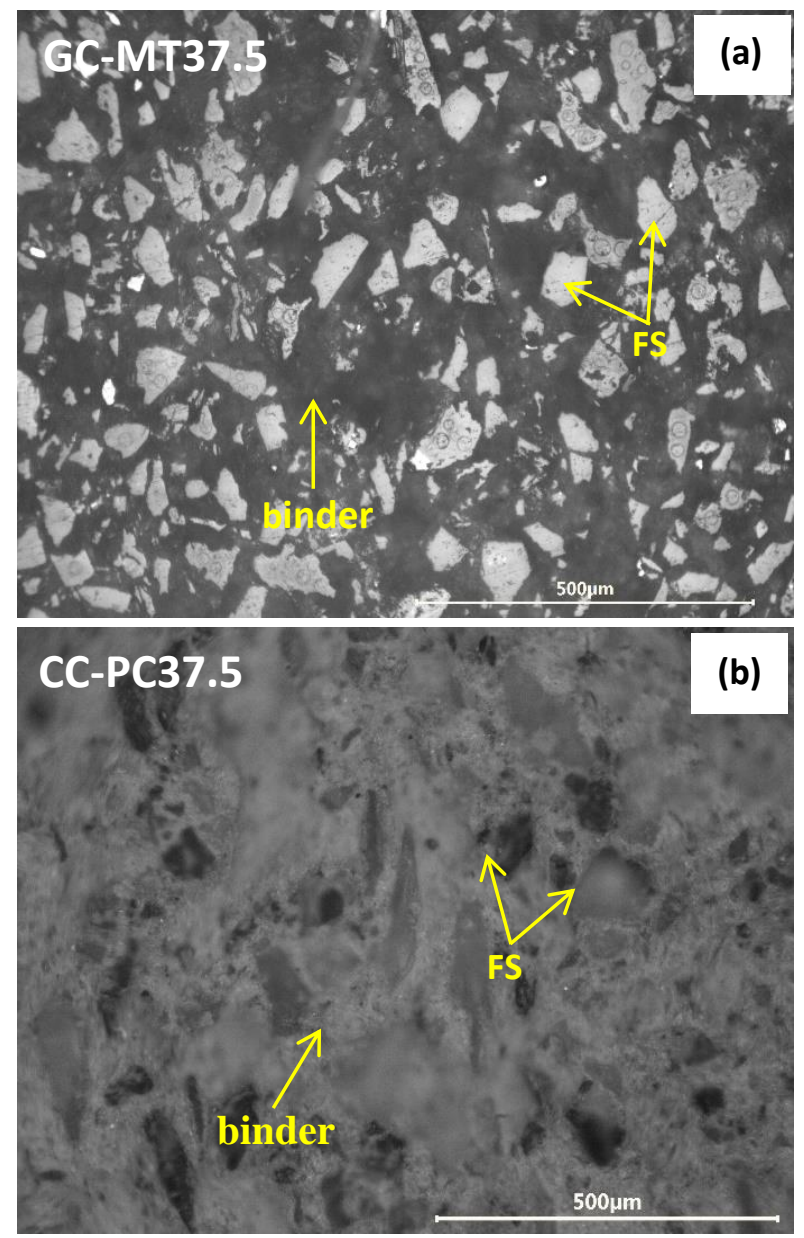

Fig. 3: Optical microscopy micrographs of polished surfaces of (a) GC-MT37.5 and (b) CC-PC37.5.

\subsection{Mechanical Tests}

The mechanical and thermomechanical tests were carried out in an air atmosphere and until the material fractured, although in the tests carried out at a temperature of $600{ }^{\circ} \mathrm{C}$ it was possible to achieve a state of steady flow, in these cases the tests were stopped at $10 \%$ of total deformation.

Figure 4 shows the macroscopic appearance of the GC samples after the mechanical compression tests under variable temperature conditions. Figure 4 (a) shows a test piece with a fragile mechanical response (test temperatures: room, $400^{\circ} \mathrm{C}$ and $500{ }^{\circ} \mathrm{C}$ ), while in figure 4 (b) a test piece with ductile mechanical response is observed (test temperature of $600{ }^{\circ} \mathrm{C}$ ). The fracture surfaces of fragile response samples revealed a process of nucleation, growth, and crack propagation that ultimately led to catastrophic failure of the material. However, the ductile response samples showed a crowding effect of the central part, without evidence of nucleation or crack propagation, it is suggested that the 
probable mechanism of deformation was softening of the geopolymer phase, keeping the FS particles without deformation, but with greater cohesion between them.
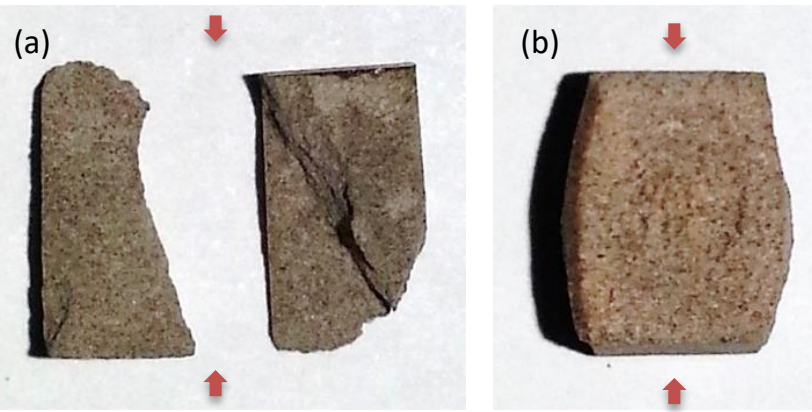

Fig. 4: Macroscopic appearance of GC samples with (a) fragile and (b) ductile mechanical response.
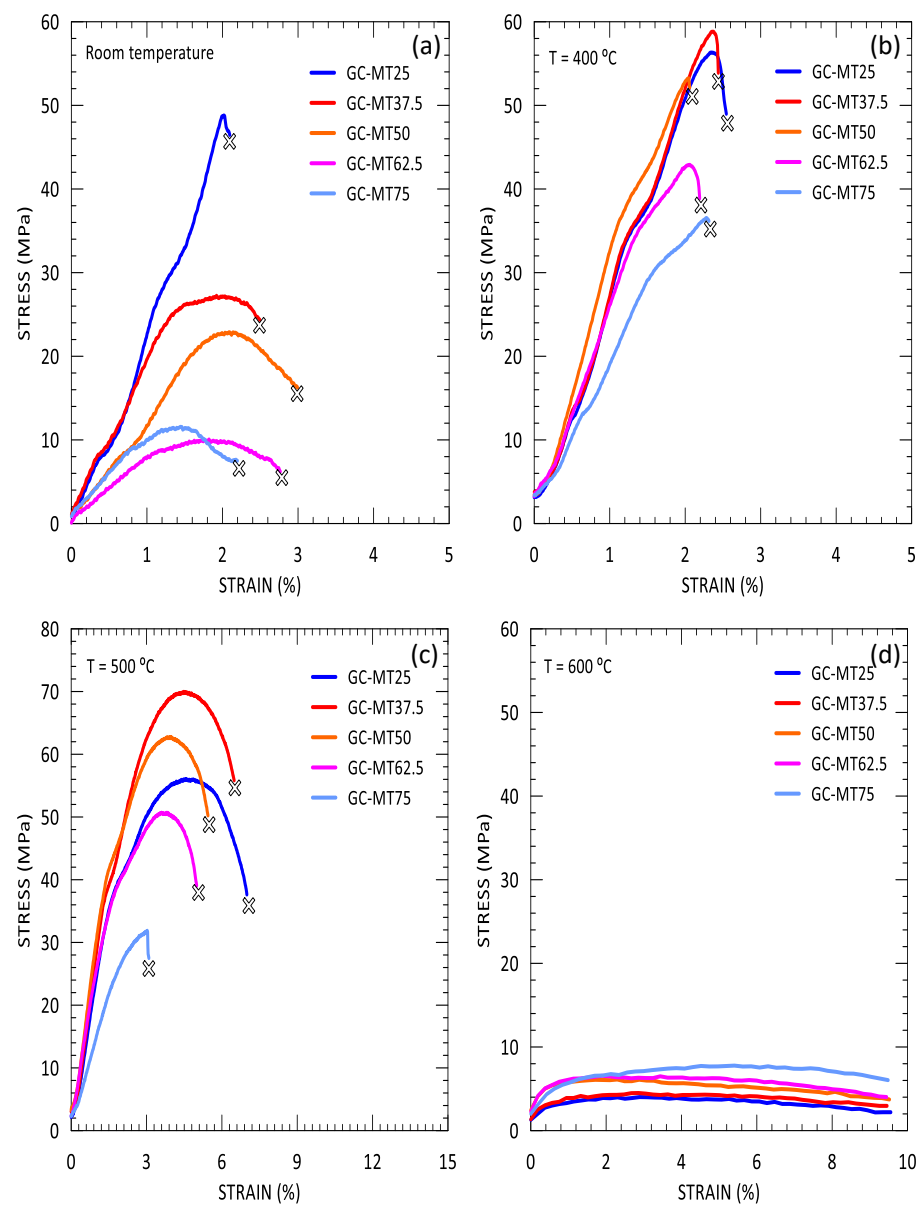

Fig. 5: Stress-strain curves of GC samples tested at (a) room temperature, (b) $400{ }^{\circ} \mathrm{C}$, (c) $500^{\circ} \mathrm{C}$ and (d) $600^{\circ} \mathrm{C}$.

Figure 5 (a) shows stress-strain curves at room temperature of the five types of GCs. A systematic decrease in maximum resistance has been identified when the volumetric fraction of MT increases from 25 to
75 vol.\%, obtaining values from 48.8 to $11.3 \mathrm{MPa}$, respectively, this result suggests that, under the test conditions, the continuous phase Geopolymeric, being the least resistant, is the one that controls the elastic deformation process of this type of materials.

Figure 5 (b) shows the stress-strain curves obtained at $400{ }^{\circ} \mathrm{C}$, where a systematic increase in the values of maximum resistances for all GC samples is observed, with respect to the tests carried out at room temperature (Figure $5(\mathrm{a})$ ), this result could suggest that the geopolymerization process was incomplete (in the tests at room temperature) and comes to completion when the test temperature is raised, which leads us to deduce that the increase in temperature leads to the binder phase cohesion better the FS particles. This is confirmed in figure 5 (c) where a slight increase in the maximum mechanical resistance is observed when the test temperature increases from 400 to $500^{\circ} \mathrm{C}$. Figures 5 (b) and 5 (c) reveal that the increase in mechanical resistance with the test temperature is more evident in concretes with a higher MT concentration. Up to this point in the analysis, only a fragile behavior of all GC samples has been identified, when they are subjected to uniaxial compression stresses from room temperature to $500 \stackrel{\circ}{\circ}$.

Between 500 and $600{ }^{\circ} \mathrm{C}$ a fragile-ductile transition occurs, finding that at $600{ }^{\circ} \mathrm{C}$ all GC samples show a completely ductile behavior, as observed in figure $5(d)$.

Figure 6 shows the mechanical and thermomechanical results for CC samples. It is observed that at room temperature (Figure 6 (a)), increases in the PC volume fraction lead to increases in maximum mechanical strength, varying from 8.5 to $32.1 \mathrm{MPa}$ when the PC increases from 25 to 75 vol\%, respectively. The thermomechanical results of CC samples at $400{ }^{\circ} \mathrm{C}$ (figure 6 (b)), compared to those obtained at room temperature (figure 6 (a)), show a significant increase in terms of maximum mechanical resistance, mainly in samples with a higher PC volumetric content (CC-PC62.5 and CC-PC75).

From test temperatures of $500^{\circ} \mathrm{C}$ (figure 6 (c)), the maximum resistance of CCs decreases slightly (figure 6 (d)). It should be noted that for CC samples with volumetric fractions of 25 and $37.5 \mathrm{vol} \%$ of PC, the effect of temperature (from room to $600^{\circ} \mathrm{C}$ ) on the maximum mechanical response in compression was not significant, in addition, compared to GC samples, ductile mechanical responses have not been identified, with the fragile fracture mode being the only possible one. 

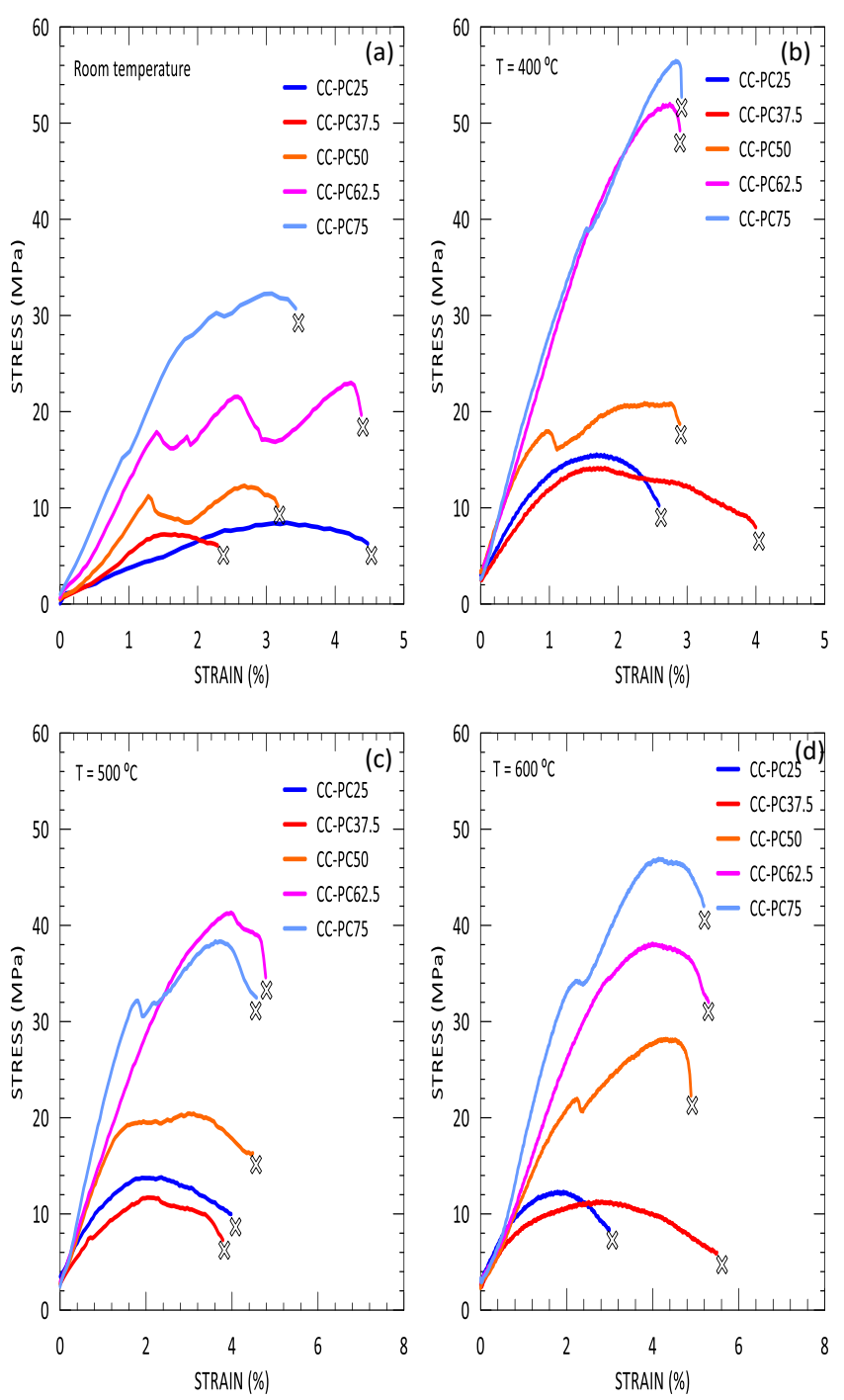

Fig. 6: Stress - strain curves of CC samples tested at (a) room temperature, (b) $400{ }^{\circ} \mathrm{C}$, (c) $500{ }^{\circ} \mathrm{C}$ and (d) $600^{\circ} \mathrm{C}$.

Fig. 7 shows the relationship between the maximum uniaxial compressive stress measured at room temperature and the binder volumetric fraction of the studied concretes (mining tailings in geopolymeric concretes and Portland cement in conventional concretes). The difference in behavior is clearly appreciated, while in geopolymeric concretes there is a decrease in maximum resistance when the concentration of the binder phase increases (blue line in Fig. 7), in conventional concretes an increase is observed of maximum resistance when the binder phase concentration increases (red line in Fig. 7).

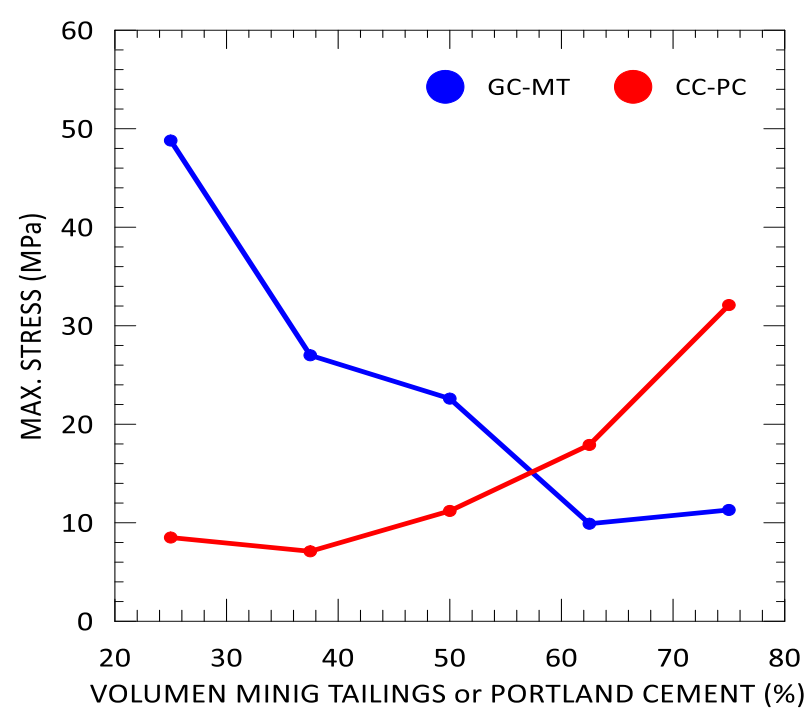

Fig. 7. Relationship between the binder volumetric fraction (mining tailings or Portland cement) and the maximum resistance to compression for the two types of concretes studied.

Fig. 8 shows the analysis of the effect of the binder phase concentration and temperature on the maximum mechanical stress of geopolymeric concretes based on mining tailings and conventional Portland cement concretes. First, it is observed that for geopolymeric concretes the increase in the concentration of the binder phase (mining tailings) leads to a reduction in the value of the maximum mechanical resistance, in contrast to what was observed in conventional concretes, where the increase in the binder phase (Portland cement) leads to an increase in the value of the maximum mechanical resistance.

On the other hand, the increase in temperature in the mechanical compression tests leads, in both types of concrete, to an increase in the maximum mechanical resistance, this increase being more important in geopolymeric concretes. In conventional concretes, the effect of increasing the test temperature is more evident in those specimens with a higher concentration of binder phase. Finally, geopolymeric concretes show a brittleductile transition between 500 and $600^{\circ} \mathrm{C}$, showing only ductile behavior when tested at $600{ }^{\circ} \mathrm{C}$ and only brittle up to test temperatures below $500{ }^{\circ} \mathrm{C}$, conventional Portland cement concretes show, in the range of room temperature to $600{ }^{\circ} \mathrm{C}$, only a brittle behavior, typical of ceramic materials. 

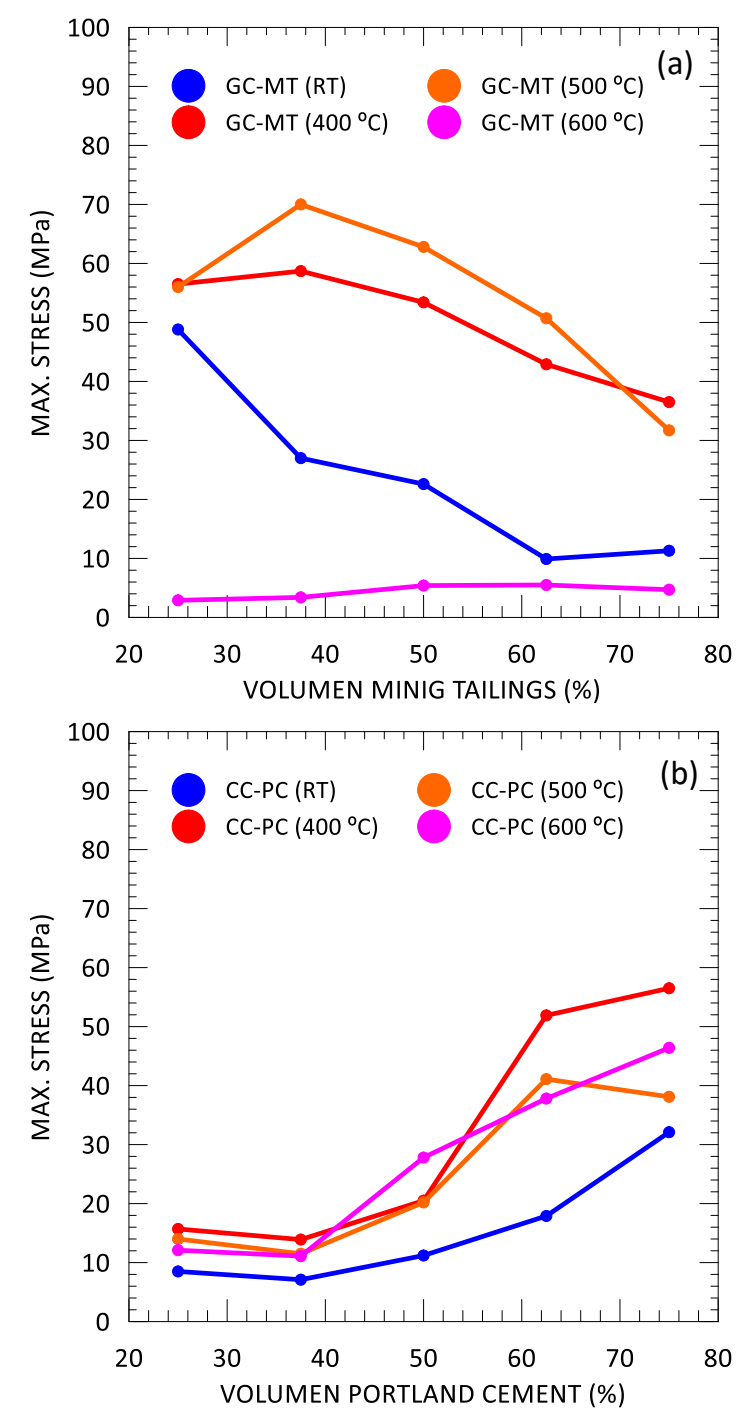

Fig. 8. Relationship between the binder phase concentration and the maximum mechanical resistance at temperatures between room temperature and $600{ }^{\circ} \mathrm{C}$ for (a) geopolymeric concretes and (b) conventional concretes.

\section{Conclusions}

Geopolymeric and conventional concretes have been successfully prepared, the former by geopolymerizing mining tailings powder, fine sand and a $9 \mathrm{M}$ aqueous solution of sodium hydroxide, and the latter by setting ordinary Portland cement.

The average particle size for fine sand and mining tailings was determined to be 100 and $40 \mu \mathrm{m}$, respectively, these results were consistent with the observed by scanning electron microscopy.

Nine crystalline phases were found in the mining tailings: Muscovite $\left(\mathrm{KAl}_{2} \mathrm{Si}_{3}\right)$, Quartz $\left(\mathrm{SiO}_{2}\right)$, Orthoclase
$\left(\mathrm{KAlSi}_{3} \mathrm{O}_{8}\right)$, Pyrite $\left(\mathrm{FeS}_{2}\right)$, Calcite $\left(\mathrm{CaCO}_{3}\right)$, Sulfur (S), Actinolite $\quad\left(\mathrm{Ca}_{2}\left(\mathrm{Mg}, \mathrm{Fe}^{+2}\right)_{5} \mathrm{Si}_{8} \mathrm{O}_{22}(\mathrm{OH})_{2}\right), \quad$ Hydrogen Arsenate Hydrate $\left(\mathrm{As}_{2} \mathrm{O}_{5}{ }^{*} 4 \mathrm{H}_{2} \mathrm{O}\right)$ y Arsenolite $\left(\mathrm{As}_{2} \mathrm{O}_{3}\right)$ and five in the fine sand: Albite $\left(\mathrm{Na}\left(\mathrm{Si}_{3} \mathrm{Al}\right) \mathrm{O}_{8}\right)$, Gypsum $\left(\mathrm{CaSO}_{4} * 2 \mathrm{H}_{2} \mathrm{O}\right)$, Quartz $\left(\mathrm{SiO}_{2}\right)$, Potassium Magnesium Aluminum Fluoride Silicate $\left(\mathrm{KMg}\left(\mathrm{Si}_{3} \mathrm{Al}\right) \mathrm{O}_{10} \mathrm{~F}_{2}\right)$ y Fluoroedenite $\left(\mathrm{NaCa}_{2} \mathrm{Mg}_{5} \mathrm{Si}_{7} \mathrm{AlO}_{22} \mathrm{~F}_{2}\right)$.

It was determined that for geopolymeric concretes the increase in the concentration of mining tailings leads to a reduction in the value of the maximum mechanical resistance, in contrast to what was observed in conventional concretes, where the increase in the Portland cement phase led to an increase in the value of maximum mechanical resistance.

The increase in temperature in mechanical compression tests led, in both types of concretes, to an increase in maximum mechanical strength, showing a more significant increase in geopolymer concretes. In conventional concretes, the effect of the increase in the test temperature is more evident in those test specimens with a higher concentration of the binder phase.

Geopolymer concretes have a brittle-ductile transition between 500 and $600{ }^{\circ} \mathrm{C}$, showing only ductile behavior when tested at $600{ }^{\circ} \mathrm{C}$ and only brittle at temperatures below $500{ }^{\circ} \mathrm{C}$, conventional Portland cement concretes show, ranged from room temperature to $600{ }^{\circ} \mathrm{C}$, only a fragile behavior, typical of ceramic materials.

\section{Acknowledgements}

This work was financed by the project Concytec Banco Mundial, through its executing unit the Fondo Nacional de Desarrollo Científico, Tecnológico y de Innovación Tecnológica (Fondecyt) within the framework of call E041-01 with contract $\mathrm{N}^{\circ} 36-2018$ FONDECYT-BM-IADT-AV and was executed in the laboratories of the Universidad Católica San Pablo.

\section{References}

[1] J. Davidovits, M. Davidovics, "Geopolymer: ultrahigh temperature tooling material for the manufacture of advanced composites", Sampe 36 (2) (1991), pp. 1939-1949.

[2] Hamdy K. Shehab, Ahmed S. Eisa, Ahmed M. Wahba, "Mechanical properties of fly ash based geopolymer concrete with full and partial cement replacement", Construction and Building Materials, vol. 126, 2016, pp. 560-565.

[3] Bo Wei, Yimin Zhang, Shenxu Bao, "Preparation of geopolymers from vanadium tailings by 
mechanical activation", Construction and Building Materials, vol. 145, 2017, pp. 236-242.

[4] Jingkun Yuan, Peigang He, Peifeng Zhang, Dechang Jia, Delong Cai, Zhihua Yang, Xiaoming Duan, Shengjin Wang, Yu Zhou, "Novel geopolymer based composites reinforced with stainless steel mesh and chromium powder", Construction and Building Materials, vol. 150, 30 September 2017, pp. 89-94.

[5] Bo Wei, Yimin Zhang, Shenxu Bao, "Preparation of geopolymers from vanadium tailings by mechanical activation" Construction and Building Materials, vol. 145, 2017, pp. 236-242.

[6] F.N. Okoye, "Geopolymer binder: A veritable alternative to Portland cement", Materials Today: Proceedings, vol. 4, Issue 4, Part E, 2017, pp. 55995604.

[7] Davidovits J., "Properties of Geopolymer Cements", First International Conference on Alkaline Cements and Concretes, 1994, pp.131-149.

[8] Wallah SE, "Drying Shrinkage of Heated-Cured Fly Ash-Based Geopolymer Concrete", Modern Applied Science 2009;3(12), pp. 14-21.

[9] Ferraris CF, Clifton JR, Stutzman PE, Garboczi EJ, "Mechanisms of degradation of Portland cementbased systems by sulfate attack", Mechanisms of Chemical Degradation of Cement-Based systems 1997; pp. 185-192.

[10] T. Bakharev, "Durability of geopolymer materials in sodium and magnesium sulfate solutions", Cement and Concrete Research, vol. 35, Issue 6, 2005, pp. 1233-1246.

[11] Wallah SE and Rangan BV, "Low-calcium fly ashbased geopolymer concrete long-term properties", Research Report GC2, Faculty of Engineering, Curtin University of Technology, 2006.

[12] Kong DLY and Sanjayan JG., "Effect of elevated temperature son geopolymer paste, mortar and concrete", Cement and Concrete Research 2010;40(2), pp. 334-339.

[13] Jeff Borger, Ramon L. Carrasquillo, David W. Fowler., "Use of recycled wash water and returned plastic concrete in the production of fresh concrete", Advanced Cement Based Materials, vol. 1, Issue 6, 1994, pp. 267-274.

[14] Mónica Moreno-Brush, Johan Rydberg, Nadia Gamboa, Ilse Storch, Harald Biester, "Is mercury from small-scale gold mining prevalent in the southeastern Peruvian Amazon?, Environmental Pollution, vol. 218, 2016, pp. 150-159.
[15] Joni Safaat Adiansyah, Michele Rosano, Sue Vink, Greg Keir, Jason R. Stokes, "Synergising water and energy requirements to improve sustainability performance in mine tailings management", Journal of Cleaner Production, vol. 133, 2016, pp. 517.

[16] Joni Safaat Adiansyah, Michele Rosano, Sue Vink, Greg Keir, "A framework for a sustainable approach to mine tailings management: disposal strategies", Journal of Cleaner Production, vol. 108, Part A, 2015, pp. 1050-1062. 